\title{
Sedes web
}

\section{La pesca como patrimonio cultural}

Utilizamos Internet metafóricamente como un océano en el que adentrarse para la búsqueda de sedes Web que reflejen desde distintos puntos de vista, información sobre el patrimonio pesquero. Después de un amplio rastreo, llegamos a la conclusión de que existen numerosos enfoques desde los que se puede analizar el patrimonio pesquero en su globalidad.

Si comenzamos por seleccionar la información encontrada acerca del patrimonio pesquero o el patrimonio y la pesca en general, encontramos documentos que nos sitúan dentro del concepto exacto de patrimonio pesquero desde el punto de vista del cuidado de la especie, de su repercusión socioeconómica, legal y de mercado. Así, en Perspectivas para el Sector Pesquero (www.ugm.cl/pacifico/monograf/pesca2000.htm), Jorge Martínez Busch nos habla en un extenso documento del concepto de Patrimonio Pesquero, analizando los vectores que lo sostienen y las perspectivas del mismo en ciclo corto y en ciclo largo.

Otro documento de interés por la implicación de las regiones en la protección de este patrimonio en particular es el relativo al Encuentro internacional pesca artesanal y soberanía alimentaria (www.alliance21.org/es/colleges/fish/docs/fish_cuba _es.rtf), celebrado en la Habana (Cuba), donde se reunieron pescadores artesanales representantes de comunidades y organizaciones de pescadores provenientes de Africa, Europa, América Latina y del Ministerio de la Pesca de la República de Cuba, y expresaron entre otras cosas, que "las comunidades de la pesca artesanal al igual que las comunidades de campesinos, se encuentran afectadas por la contradicción entre las políticas de economía de libre mercado y los aspectos de sustentabilidad ambiental, equidad social y seguridad y soberanía alimentaria".

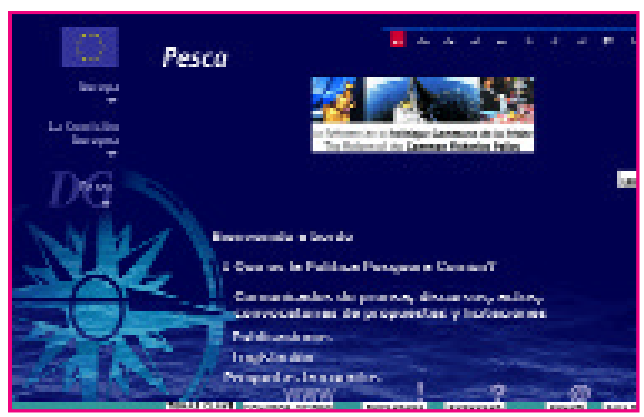

Dentro del marco legal que lo sostiene, podemos destacar algunas sedes que reflejan una amplia información sobre la política y la legislación concerniente a este sector. Así, en la Web de la Dirección General de Pesca de la Unión Europea (europa.eu.int/comm/fisheries/policy_es.htm), nos encontramos con la Politica Pesquera Común, asi como con publicaciones, normativa vigente $y$ preguntas más frecuentes relativas al mundo de la pesca.

Más información al respecto, la encontramos en la sede denominada Ocean Law (ww.oceanlaw.net/), en la que se recoge entre otras informaciones, una guia internacional de legislación para pescadores y un boletín internacional para pescadores, así como una lista de discusión sobre las leyes internacionales del sector. Esta Web sólo puede consultarse en inglés.

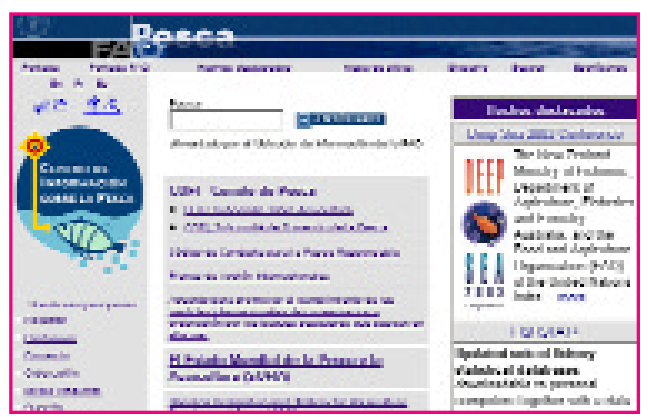

La Sede Web del Centro de Información sobre pesca de la FAO (www.fao.org/fi/inicio_all.asp), funciona como un portal en el que se recogen las últimas novedades relativas a: El Estado Mundial de la Pesca, Recursos Pesqueros, Políticas Pesqueras, Acuerdo para promover el cumplimiento responsable de conservación y ordenación por buques pesqueros que pescan en alta mar, Aspectos socioeconómicos, Medio Ambiente, Recursos, Red de Información, Biblioteca y Publicaciones, entre otros.

Y dejando a un lado la vertiente de protección legal y normativa comunitaria, nos adentramos ahora en el aspecto antropológico que rodea al mundo de la pesca. Para ello, hemos encontrado dos sedes que pueden resultar representativas de la repercusión que la pesca como "modus vivendis", ha tenido y tiene aún en pueblos que todavia hoy conservan sus costumbres y ritos mediatizados por el mar. 


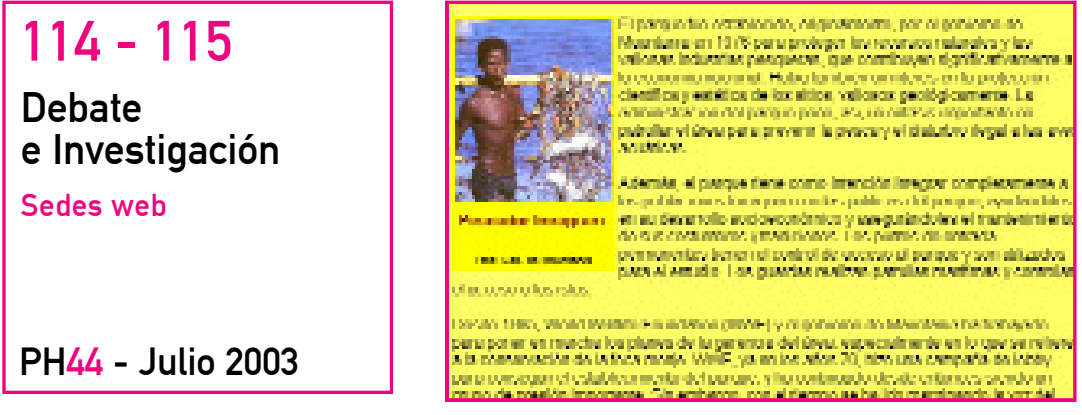

He ahí la Web de Los Imraguen, protectores de la cultura y naturaleza mauritana (www.afrol.com/ es/Paises/Mauritania/cult_imraguen.htm). En 1989, el parque nacional mauritano 'Banc d'Arguin' fue admitido en la lista de los sitios declarados patrimonio mundial de la UNESCO. Franjeando la costa atlántica del desierto del Sáhara, el parque se compone de dunas de arena, pantanos costeros, pequeñas islas y aguas costeras. Sin embargo, es más conocido por su biodiversidad (pájaros, pescado, tortugas, delfines, etc.) y sus recursos dentro de la industria pesquera, manejados cuidadosamente por los pescadores locales del pueblo Imraguen (unos 1.000 pescadores han habitado la zona desde decenas de millares de años). Los barcos utilizados son tradicionales y las técnicas de pesca no han cambiado desde el siglo XV en que fueron introducidas por los portugueses. Pero la sobreexplotación pesquera extranjera en el parque sigue constituyendo una amenaza para este patrimonio universal.

Otra sede a destacar es la dedicada a Ritos garífunas de la pesca y el mar (www.stanford.edu/group/ arts/honduras/discovery_sp/customs/ritual/fish.html), nos ilustra sobre las ceremonias y las creencias que esta comunidad de pescadores tiene en torno al mar.

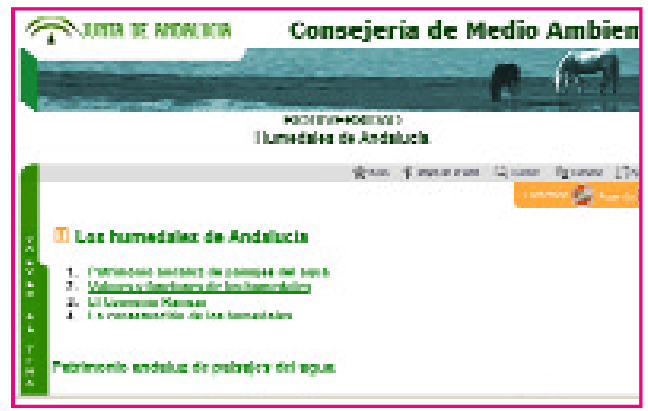

Ya dentro de la Comunidad Andaluza, destacamos el papel primordial que los Humedales juegan dentro de la protección del Medio Ambiente, así como dentro del Patrimonio Cultural. Sobre este tema nos ilustra la Web de la Consejería de Medio Ambiente acerca de Los Humedales de Andalucía: (www.juntadeandalucia.es/medioambiente/ humedales/humedal.html), donde se analizan los siguientes temas a destacar: Patrimonio andaluz de paisajes del agua, Valores y funciones de los humedales, El Convenio Ramsar y La conservación de los humedales.
Los Humedales, un incomparable paisaje cultural (www.agualtiplano.net/humedales/humedales.htm), sección que refleja aspectos sobre su historia, los problemas de ordenación, su relación con el mundo del arte, la literatura o la música, así como las distintas Convenciones celebradas sobre el tema de entre las que destacamos la Convención Ramsar, y dentro de ella, la Resolución VIII.19 sobre los principios orientadores para tomar en cuenta los valores culturales de los humedales para el manejo efectivo de los sitios: (www.ramsar.org/key_res_viii_19_s.htm)

También dentro de nuestra comunidad cabe hacer mención a la página Web dedicada al Proyecto Argos: (argos.sigadel.com/presentacion.php), iniciativa del Área de Desarrollo Local de la Diputación de Huelva para la puesta en marcha de una red de cooperación entre zonas dependientes de la pesca.

Como referencia a las artes y tradiciones históricas en torno a la pesca en Andalucia, incluido en la sede Web de la Fundación Casa de Medina Sidonia (www.fcmedinasidonia.com/1historias_2.htm), dentro de un apartado dedicado a Historias Privadas, encontramos un grabado antiguo de la Almadraba en Conil, acompañado de un amplio documento sobre la pesca de Almadraba en el Viejo Régimen. Además, se hace incapié en la necesidad de impedir el derribo de La Casa Chanca Fortaleza de Zahara, construida en el siglo XV, antiguo palacio de las Pilas, en cuyo patio se colgaban los atunes para limpiarlos y hacerlos cuartos. Hoy día se conserva casi completa y está considerada como instalación industrial, única en el mundo, por su antigüedad y naturaleza.

Actualmente está aprobado el derribo de las edificaciones interiores, para construir un hotel de 5 estrellas dentro de la muralla, por lo que desde la sede referida, se pide ayuda para impedirlo a los responsables de Europa, para que apliquen los medios legales disponibles para ello.

En lo relativo al turismo y la pesca, destacamos como enclave de interés turístico, un lugar del Algarve portugués, el Hotel Vila Galé Albacora (antigua cofradía de pescadores Arraial Ferreira Neto): (www.golfbenamor.com/gb/albacora.htm), situado en el Parque Natural de Ría Formosa con la isla de Tavira y el mar a la vista. Inspirado en la arquitectura local, sus 162 habitaciones, son el resultado de la recuperación de las antiguas casas de pescadores que vivieron y trabajaron alli. Es una importante referencia de la pesca del atún en el Algarve. Actualmente, cuenta con un museo/centro de interpretación de la historia del lugar, así como con una escuela y una iglesia del poblado original.

Los museos del mar son también lugares a destacar dentro del patrimonio pesquero. Entre los más interesantes destacamos el Museo Maritimo del Cantábrico, Museo Naval de San Sebastián y el Museo-Aula del Mar de Málaga. 
El Museo Marítimo del Cantábrico (www.eldiario montanes.es/patrimonio/museos/mus16.htm), nos muestra fondos sobre la relación del hombre con el mar, con más de 9.000 objetos provenientes de diversos lugares. La exposición se articula con las siguientes secciones: sección de Biología Marina, con piezas casi centenarias provenientes de la Estación de Biología Marina de Santander; sección de Historia Marítima, centrada en aspectos relacionados con el comercio, el deporte y la guerra; y por último, la sección de Tecnología Maritima, que dispone de una de las mejores colecciones de herramientas de construcción naval de España. Pero entre sus proyectos y actividades más destacados destacan los relacionados con el plano arqueológico, con proyectos de excavaciones sobre el antiguo "Portus Victoriae luliobrigensium", entre otros.

El Museo Naval de San Sebastián (www.gipuzkoa. net/kultura/museos/um/castella/01 untzic.htm), abierto al público en 1991, nace con el propósito de contribuir a la recuperación del Patrimonio Maritimo Vasco, entendiendo por tal el conjunto de manifestaciones intelectuales y materiales producto de la actividad humana relacionada con el mar y la navegación.

El Museo-Aula del Mar de Málaga (www.veterinaria. org/asociaciones/auladelmar/quees.htm), está dedicado entre sus numerosas actividades a la educación ambiental, protección de las especies, investigación y formación en cultivos marinos y participación y divulgación, con acciones de protección por todo el litoral de la comunidad.

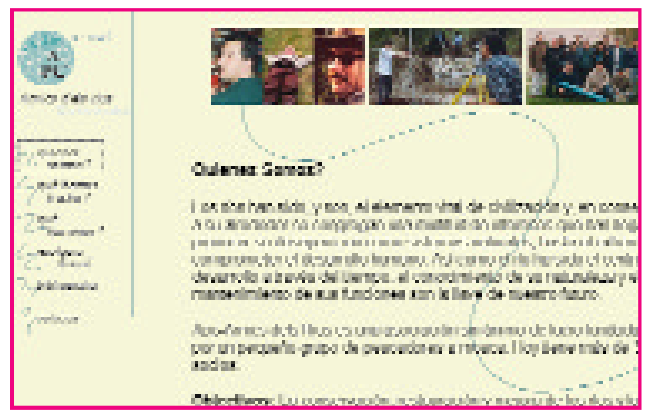

Otro aspecto que no hay que olvidar es el relacionado con las asociaciones a favor de la protección del patrimonio del mar, de entre la que destacaremos la sede Web de Apc-Amics dels Rius (www.geocities.com/RainForest/Vines/3475/inicics.htm) , asociación sin ánimo de lucro fundada en 1990 por un pequeño grupo de pescadores a mosca. Hoy tiene más de 300 socios. Entre sus objetivos principales destacan la conservación, restauración y mejora de los ríos y lagos de Cataluña. El estudio de los ecosistemas acuáticos continentales, y la reivindicación de un sistema de gestión conservacionista de los recursos hídricos, basado en las relaciones entre el agua y sus ecosistemas.

Finalmente, de entre todas las publicaciones analizadas sobre el sector, cabe destacar Mar y Pesca (www.iim.csic.es/MaryPesca/Julio2002/Pagina2.html), suplemento mensual del Faro de Vigo. En el número de Julio de 2002, destaca un proyecto de la Federación de Vecinos de Vigo para "dar la cara al mar". Proponen la creación de una fundación para conservar, recuperar y promocionar el patrimonio marítimo de la Ría viguesa. El proyecto vecinal pretende recuperar buques históricos como el Bernardo Alfageme para convertirlos en centros de interpretación marítimos.

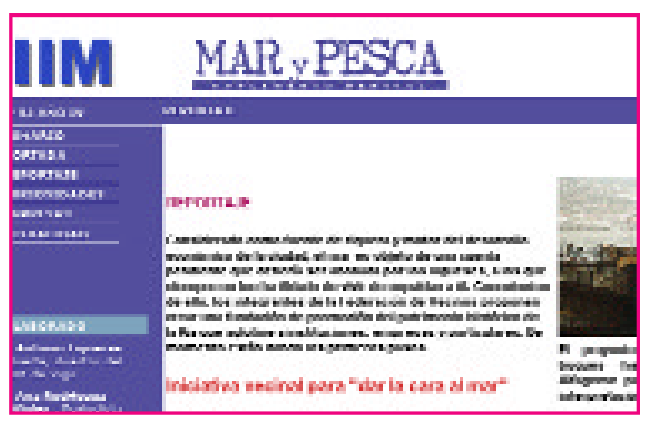

Como conclusión, y después del recorrido realizado por todas las sedes Web relacionadas con este tema, apreciamos la variedad de información existente sobre el sector si lo analizamos desde diversos puntos de vista. Así sea la valoración del patrimonio pesquero en centros de interpretación, museos, etc, como en su regulación legal y política. También destacamos la profusión de asociaciones en defensa de la conservación del patrimonio marítimo, el aspecto antropológico en los ritos y técnicas ancestrales persistentes todavía en algunos pueblos, y las publicaciones y portales temáticos de calidad especializados en el tema.

Como complemento a la información analizada, relacionamos a continuación una serie de direcciones útiles sobre el mundo de la pesca: portales, revistas electrónicas o enlaces para el pescador:

Links a Webs relacionadas con el mundo de la pesca:

Biología y conservación de ríos y salmónidos: www.arrakis.es/ aems/enlaces.htm

Revistas electrónicas y portales de pesca:

Todopesca.com (Links a Webs relacionadas con la pesca): www.todopesca.com/links/lindex.htm

Todopesca.com (Revistas electrónicas y portales de pesca): www.todopesca.com/links/lportal01.htm

Enlaces para el pescador:

A Pescar Tocan: www.cotosdepesca.com/enlaces.asp 